\title{
Phylogenetic clustering among aggressive competitors: evidence from odonate assemblages along a riverine gradient
}

\author{
Victor S. Saito ${ }^{1}$ Francisco Valente-Neto ${ }^{2}$ Marciel Elio Rodrigues ${ }^{2}$. \\ Fabio de Oliveira Roque ${ }^{3,4} \cdot$ Tadeu Siqueira $^{5}$
}

Received: 18 September 2015 / Accepted: 20 April 2016 / Published online: 9 May 2016

(C) Springer-Verlag Berlin Heidelberg 2016

\begin{abstract}
Studies on phylogenetic community ecology usually infer habitat filtering when communities are phylogenetically clustered or competitive exclusion when communities are overdispersed. This logic is based on strong competition and niche similarity among closely related species-a less common phenomenon than previously expected. Dragonflies and damselflies are good models for testing predictions based on this logic because they behave aggressively towards related species due to mistaken identification of conspecifics. This behavior may drive communities toward phylogenetic overdispersion if closely related species frequently exclude each other. However,
\end{abstract}

Communicated by Scott D Peacor.

Electronic supplementary material The online version of this article (doi:10.1007/s00442-016-3642-1) contains supplementary material, which is available to authorized users.

Victor S. Saito

victor.saito@gmail.com

1 Programa de Pós-Graduação em Ecologia e Recursos Naturais, Universidade Federal de São Carlos, Rod.

Washington Luiz km 235, 13565-905 São Carlos, São Paulo, Brazil

2 Programa de Pós-Graduação em Ecologia e Conservação, Universidade Federal de Mato Grosso do Sul, 79070-900 Campo Grande, Mato Grosso do Sul, Brazil

3 Centro de Ciências Biológicas e da Saúde, Universidade Federal do Mato Grosso do Sul, 79070-900 Campo Grande, Mato Grosso do Sul, Brazil

4 Centre for Tropical Environmental and Sustainability Science, James Cook University, Cairns, QLD, Australia

5 Departamento de Ecologia, Instituto de Biociências, UNESP, Univ Estadual Paulista, 13506-900 Rio Claro, São Paulo, Brazil phylogenetically clustered communities could also be observed if habitat filtering and/or competitive asymmetry among distantly related species are major drivers of community assembling. We investigated the phylogenetic structure of odonate assemblages in central Brazil in a watershed characterized by variations in stream width, vegetation cover, aquatic vegetation, and luminosity. We observed general clustering in communities according to two indices of phylogenetic structure. Phylogenetic beta diversity coupled with Mantel tests and RLQ analysis evidenced a correlation between the riverine gradient and phylogenetic structure. Larger rivers with aquatic vegetation were characterized by anisopterans, while most zygopterans stayed in small and shaded streams. These results indicate niche conservatism in Odonata habitat occupancy, and that the environment is a major influence on the phylogenetic structure of these communities. We suggest that this is due to clade-specific ecophysiological requirements, and because closely related species may also have competitive advantages and dominate certain preferred habitats.

Keywords Community assembly · Ecophylogenetic . Ecophysiological hypothesis · Dragonfly · Damselfly

\section{Introduction}

The competition-relatedness hypothesis predicts that congeners will experience stronger competition because they share numerous phenotypic characters, so they should exploit the environment in a similar fashion (Cahill et al. 2008). Recently, along with the concepts of limiting similarity and niche conservatism, the competition-relatedness hypothesis has significantly influenced the field of phylogenetic community ecology (Webb 2000; Cavender-Bares 
et al. 2009). This new field uses the probability of the cooccurrence of closely related species to understand contemporary community assembly (Webb et al. 2002; Cavender-Bares et al. 2009). Based on niche conservatism, phylogenetic community ecology assumes that increased relatedness among species occurring simultaneously (i.e., phylogenetic clustering) is due to habitat filtering, since species with similar niches co-occur more than expected by chance. The opposite pattern, lower relatedness among cooccurring species, could be due to the competition-driven exclusion of closely related species that present significant niche overlap.

Although successful results have been reported (Cavender-Bares et al. 2004; Vamosi and Vamosi 2007), phylogenetic community ecology has recently faced criticism because pairs of closely related species experience lower competitive interference than pairs that are only distantly related (Mayfield and Levine 2010; Godoy et al. 2014). For example, greater competitive asymmetry among distant relatives can also drive phylogenetic clustering (Mayfield and Levine 2010). We therefore suggest that predictions based on this field's logic could be tested more efficiently in systems in which strong competition among closely related species is well documented and expected.

In this sense, Odonata are strong candidates for testing phylogenetic community ecology predictions, as previous evidence indicates intense aggression among closely related species (i.e., Anderson and Grether 2011). Two factors explain such aggressive behavior: first, closely related and similar Odonata species can experience exploitative and interference competition for food, space, and mating sites, leading individuals to attack others they deem competitors (Singer 1989; Corbet 1999; Worthen and Patrick 2004). Second, the mistaken-identity hypothesis (Singer 1989) states that imperfect recognition of conspecifics can cause individuals to attack similar species (Tynkkynen et al. 2006; Anderson and Grether 2011). According to this hypothesis, odonates will attack similar individuals with or without correctly recognizing them as conspecifics or heterospecifics; otherwise, possible competition for mates would be energetically disadvantageous (Singer 1989; Schultz and Switzer 2001). Mistaken aggression may also occur because Odonata brains cannot quickly distinguish conspecific from other similar species (Grether 2011). This means that we can expect Odonata assemblages to have an overdispersed phylogenetic structure because intense aggression results in lower co-occurrence of closely related species than expected for a random assembly.

From a different perspective, there is evidence for strong habitat filtering and ecological partitioning that enable the coexistence of closely related odonates (Siepielski et al. 2011; Siepielski and McPeek 2013). Environmental filtering along a longitudinal riverine gradient can select species with different preferences for stream width and forest cover because species have varying ecophysiological requirements and thermoregulation behaviors (the ecophysiological hypothesis, De Marco Jr. et al. 2015). For example, sunlit streams and rivers favor large ectothermic species due to the possibility of direct exposure to the sun, while small ectothermic odonates prefer shaded streams that have constant and steady temperatures (De Marco and Resende 2004). Consequently, if environmental drivers are important, local odonate assemblages should be phylogenetically clustered, because closely related species tend to have similar environmental requirements. This implies that we should also expect variations in the phylogenetic structure of assemblages (i.e., phylogenetic beta diversity) according to the riverine landscape. Thus, phylogenetic beta diversity may indicate whether clades are randomly distributed in the watershed or environmental variation determines their spatial distribution.

On the basis of these contrasting expectations, we investigated the phylogenetic structure of adult odonate assemblages along a riverine system that varies significantly in altitude, width, luminosity, aquatic vegetation, and forest cover. Our study aimed to shed light on whether assemblages are phylogenetically overdispersed, which would suggest that intense aggression among closely related species is a major driver, or if they are phylogenetically clustered along the riverine gradient because of similar ecophysiological requirements (Fig. 1).

\section{Materials and methods}

\section{Study area and sampling}

We carried out the study in a riverine network on the Bodoquena Plateau, located in the southwest of Mato Grosso do Sul, Brazil (Fig. 2). The Betione River watershed belongs to the Miranda River basin, a subunit of the Upper Paraguay River which also holds part of the Pantanal wetlands. The region is characterized by a transition between the Cerrado and Atlantic rainforest. The landscape of the region is a mosaic of native vegetation patches due to cattle ranching. We selected 44 unique segments of the Betione watershed, from headwaters to the mainstream. In these segments we actively collected Odonata adults over the course of an hour using an entomological net along a 100-m transect parallel to the stream banks. We conducted sampling once at each site on sunny days between 10:00 and 15:00 h due to known thermal restrictions in odonates (sampling details in Valente-Neto et al. 2016; Rodrigues et al. 2016). This method has been effectively used in other studies (e.g., Juen and De Marco 2011). Moreover, we used taxonomic keys and original descriptions to identify the specimens 


\section{Regional pool}

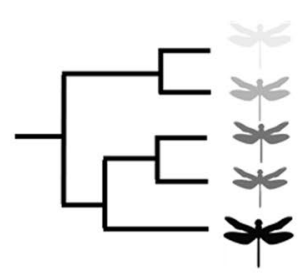

(a)

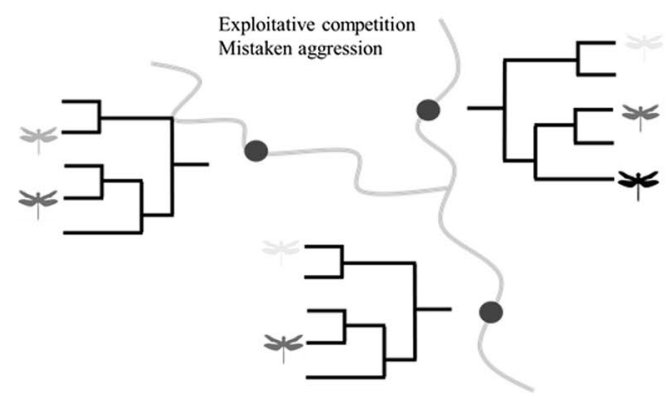

Fig. 1 Hypothesis explaining the phylogenetic structure of Odonata assemblages in riverine habitats. a Closely related species may cooccur less than expected by chance due to exploitative competition

(Lencioni 2005, 2006; Garrison et al. 2006, 2010; Heckman 2006, 2008). Voucher specimens are deposited in the Federal University of Mato Grosso do Sul's Zoological Collection (ZUFMS).

\section{Environmental variables}

Aiming to characterize the riverine system, we measured stream altitude, width, and luminosity, and we evaluated forest cover and proportion of aquatic vegetation for all sample sites. A previous study used the same dataset and showed that these variables were the most important influences on the structures of larval and adult odonate communities (Valente-Neto et al. 2016). We measured altitude using a GPS device and established stream width once every $6 \mathrm{~m}$ for a total of $30 \mathrm{~m}$ (five measurements). We also estimated luminosity using three digital photographs of the canopy taken from the middle of the stream/river. The images were analyzed with Image J (version 1.47, Wayne Rasband, National Institutes of Health, USA). We first transformed the image to black and white and then measured the white pixel area of each photograph, which represented the area where light passes through the canopy. The percentage of forest cover was calculated using ArcGis (version 10.1 ESRI, Redlands, CA, USA), based on a digital map of forest coverage with a resolution of $30 \mathrm{~m}$, as provided by the Environmental Institute of Mato Grosso do Sul State. We established a buffer of $250 \mathrm{~m}$ from the middle of each sampling point as a means of estimating (b)

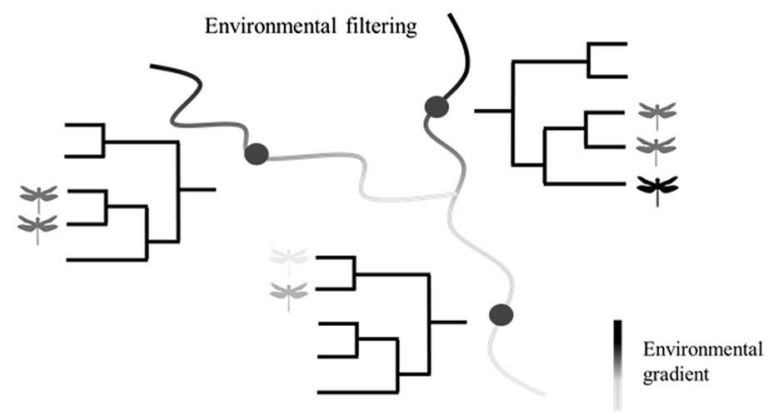

and mistaken aggression, or $\mathbf{b}$ closely related species may co-occur more often than expected by chance due to similar environmental preferences of related species

the percentage of forest cover. This distance was important considering that some odonate adults only disperse short distances $(\leq 500 \mathrm{~m}$ ) (Keller and Holderegger 2013). The proportion of aquatic vegetation was visually estimated in three $10-\mathrm{m}$ reaches.

We created an environmental distance matrix among streams using Euclidean distances and standardized values of altitude, width, luminosity, forest cover, and aquatic vegetation. This environmental distance matrix represented the riverine gradient, where headwater streams had higher altitudes, smaller widths, and lower proportions of aquatic vegetation and luminosity than larger rivers. We arcsine square-root transformed the percentages of aquatic vegetation and forest cover and we converted the numerical continuous variables to logarithms before calculating the distance matrix.

\section{Phylogeny}

We created a topological phylogeny of Odonata from our species pool (Sanderson et al. 1998) as a surrogate for phylogenetic relatedness (see Online Resource 1 in the Electronic supplementary material, ESM). We used topological taxonomic distances because topological distances or estimated branch lengths (using molecular distance or divergence time) usually show similar community patterns (Webb et al. 2002; Ives and Helmus 2010). We used six taxonomic levels (suborder, superfamily, family, subfamily, genus, and species) to create the tree based on recent 

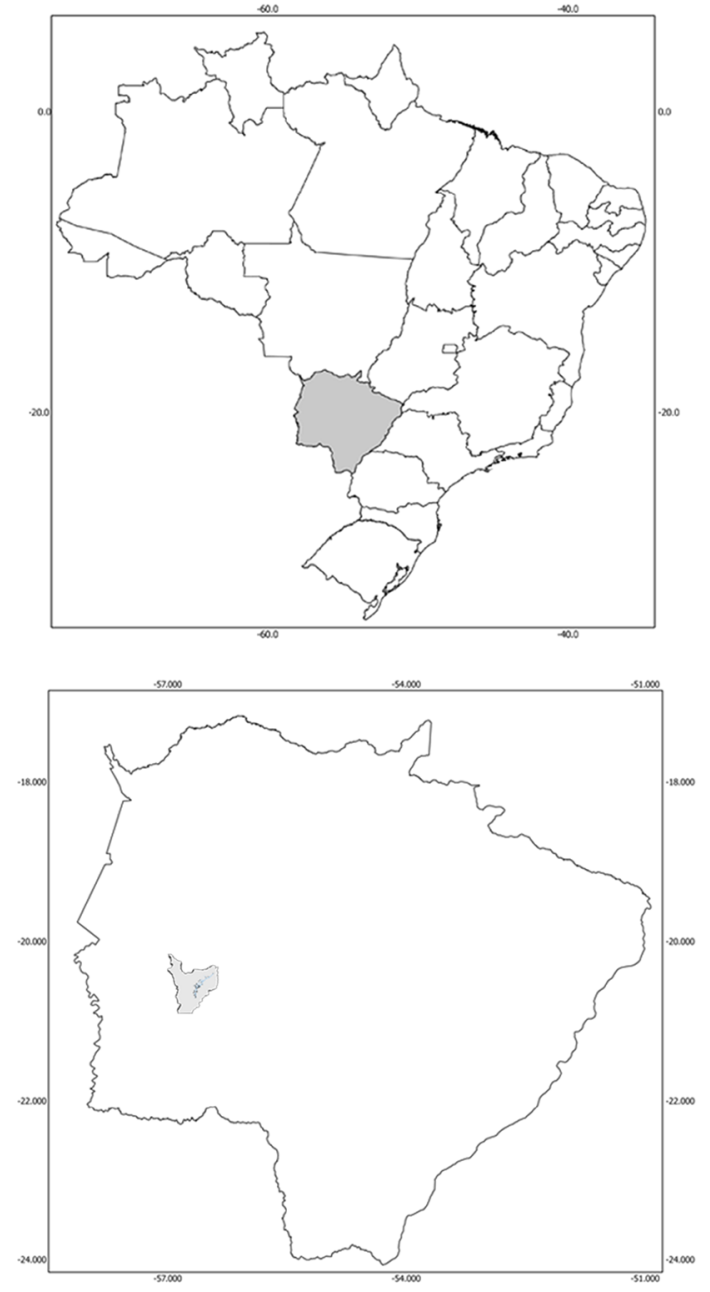

Fig. 2 Locations at which the 44 Odonata assemblages in the Betione watershed were sampled (modified from Valente-Neto et al. 2016). Samples were taken from segments of the watershed ranging

systematic reviews of Odonata phylogeny (Rehn 2003; Dumont et al. 2010; Dijkstra et al. 2014). Although the phylogeny of Odonata is still debated, we used the most comprehensive and recent data available (Dijkstra et al. 2014). We calculated the phylogenetic distance matrix with the cophenetic distances among species in the supertree (Webb 2000).

\section{Data analysis}

We calculated the metrics of the phylogenetic community structure using Mean Nearest Neighbor Distance (MNND) and Mean Pairwise Distance (MPD) (Webb 2000). MNND is calculated as the mean distance to the closest relative individual (or species when using only presence/absence data) between all individuals (or species) in a community (Webb 2000). The MNND metric

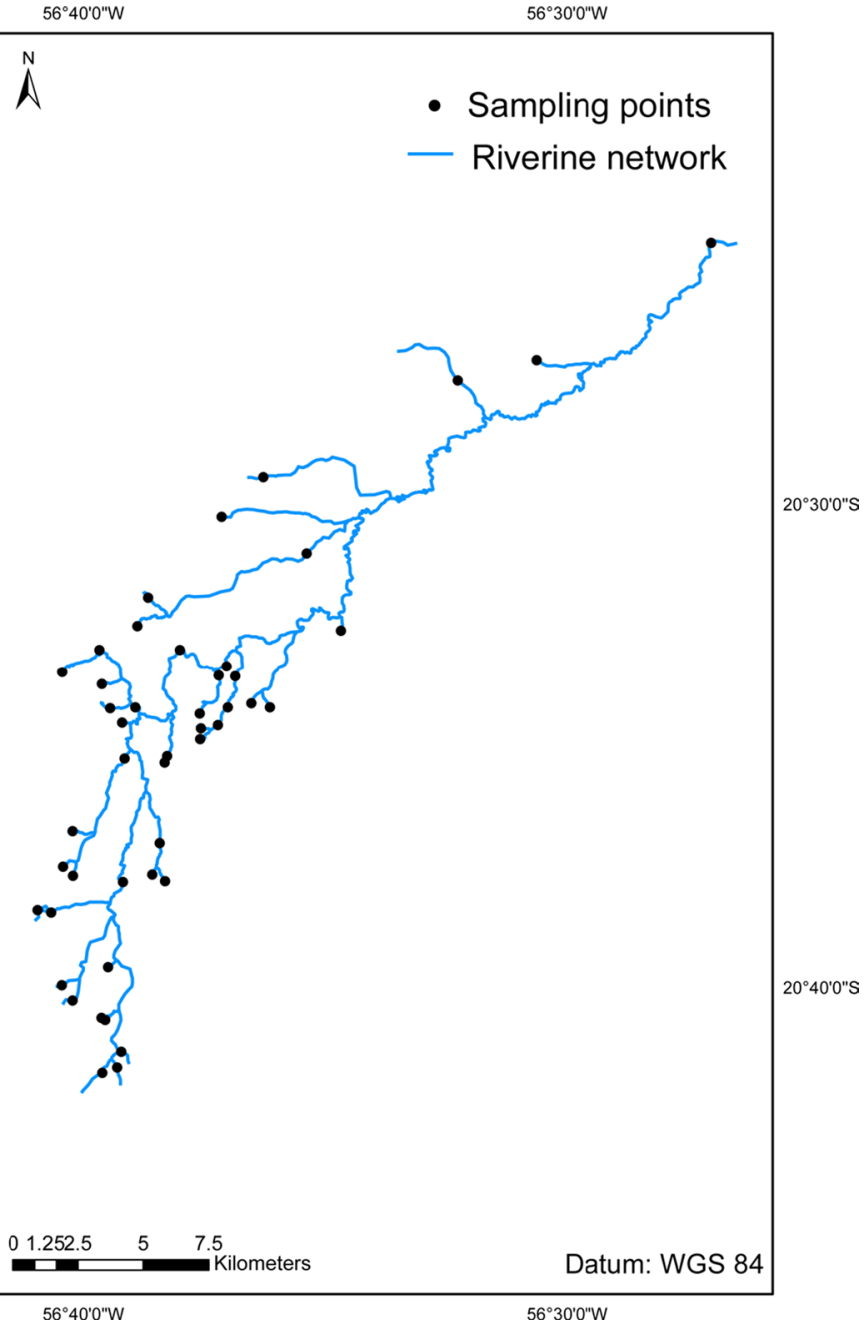

from headwaters to the mainstream. At each site, we sampled adults and measured altitude, width, percentage of shading, percentage of forest cover, and aquatic vegetation

is similar to the species-to-genus ratio and influenced less by higher levels of phylogenetic structure (Webb 2000). MPD is calculated as the mean phylogenetic distance among all individuals (or species) in a community, thereby capturing the assemblages' whole phylogenetic structure. To test whether the phylogenetic structure of the examined assemblages was more clustered or dispersed than expected by chance, we used the Nearest Taxon Index (NTI) and Net Relatedness Index (NRI). These are the standardized effect size of MNND and MPD, respectively. NTI and NRI compare the observed values of MNND and MPD to null values obtained using the null model "taxa shuffle"; the model randomizes 1,000 times the rows and columns of the matrix of phylogenetic distance among species (Kembel 2009). The "taxa shuffle" null model was most appropriate because it randomizes only the location of the taxa in the distance 
matrix, thereby constraining the richness and the abundance of samples (Swenson 2014). We used both NTI and NRI because NTI is more prone to detect over-dispersion while NRI is more keen to show clustering (Kraft et al. 2007). We used incidence and abundance data in all our analyses because density can affect competition and habitat filtering can occur at the species level (Swenson et al. 2012). The overall clustering or over-dispersion was confirmed with two-tailed Wilcoxon tests in NTI and NRI results. If NTI or NRI were higher than zero, we would infer an overall over-dispersion. Alternatively, indices significantly lower than zero indicate clustering (Swenson and Enquist 2009).

We calculated phylogenetic beta diversity among assemblages with the betaMPD and betaMNND indices. These indices are analogous to MPD and MNND. In this way, betaMPD estimates the mean phylogenetic distance among individuals (or species) among pairs of assemblages, while betaMNND estimates the phylogenetic distance among the closest related individual (or species) among pairs of assemblages (Swenson 2014). Both measures of phylogenetic beta diversity were calculated using incidence and abundance data. To observe how the phylogenetic structure affected the beta diversity in Odonata assemblages, we ran 1,000 random betaMPD and betaMNND using the "taxa shuffle" null model. We then compared the mean values of the observed betaMPD and betaMNND to values generated at random. We considered significantly lower or higher beta diversity than expected at random if the observed results were lower or higher than 975 random values.

We established a phylogenetic test for the ecophysiological hypothesis that involved checking whether changes in the phylogenetic structure of assemblages followed the riverine gradient. Therefore, we used Mantel tests between the environmental distance matrix and betaMPD and betaMNND, employing incidence and abundance data. In order to identify whether the resulting correlation was dependent on the phylogenetic structure or whether it was apparent irrespective of species relatedness, we ran 1,000 null Mantel correlations using assemblages with random phylogenetic structures (taxa shuffle). Significant phylogenetic correlations were considered to be present if observed correlations (the Mantel statistic $R$ ) were lower or higher than 975 random Mantel correlations.

To identify how the phylogenetic structure of assemblages changed along the riverine gradient, we performed a RLQ analysis. RLQ analysis is an extension of coinertia analysis, and produces a simultaneous ordination of three tables (Dolédec et al. 1996; Dray et al. 2014). Originally, RLQ analysis was used to find a combination of traits that covary with environmental characteristics, but recently a variation of it was proposed that fits phylogenetic information instead of (or together with) trait information (Pavoine et al. 2011). The analysis in this case maximizes the covariance between a linear combination of the columns of an environmental matrix and the columns of a phylogenetic distance matrix weighted by species abundance (Pavoine et al. 2011). The analysis starts with the ordination of the following matrices: $\mathrm{R}$, a matrix of environmental characteristics; $\mathrm{L}$, a matrix of species abundance; $\mathrm{Q}$, a matrix of pairwise phylogenetic distances between species. The environmental matrix $\mathrm{R}$ is standardized in the same way as done in Mantel tests (see the "Environmental variables" section) and analyzed via PCA. We analyzed matrix $\mathrm{L}$ using a correspondence analysis and matrix $\mathrm{Q}$ with a PCoA. Matrix $Q$ is a species distance matrix calculated using the square root of the sum of branch lengths of the supertree connecting the two species (Pavoine et al. 2011). RLQ analysis uses the axis of these ordinations to discover any relationships between $\mathrm{R}$ and $\mathrm{Q}$ weighted by abundances in matrix $\mathrm{L}$; it does this in a way that maximizes their squared cross-covariance (see Dolédec et al. 1996 and Dray et al. 2014 for mathematical details). Graphical observation of RLQ is achieved by ordination in a PCA fashion followed by the creation of a dot plot next to a phylogenetic tree (Pavoine et al. 2011).

\section{Results}

We collected 1226 Odonata adults, representing six families (Calopterygidae, Coenagrionidae, Protoneuridae, Aeshnidae, Gomphidae, and Libellulidae), 21 genera, and 38 species (see the ESM for a complete list). The suborder Zygoptera was represented by 21 species, and Anisoptera by 17 . Among the 21 genera found, 10 have two or more congeneric species. The two genera with more than two congeneric species were Argia and Perithemis, with four species each. On average, in each segment of the Betione watershed, we sampled eight species and 28 individuals.

We found negative values of NTI in 32 analyzed assemblages (out of 44) using incidence and abundance data (Fig. 3). We observed significant phylogenetic clustering in four of those (three in abundance data)-i.e., the observed MNND value was lower than 975 null values (Table 1). The remaining 12 assemblages showed positive values of NTI, and none of them presented significant phylogenetic overdispersion (see Table 1 for exact $P$ values). As expected, signals of phylogenetic clustering were more evident in NRI. Based on incidence and abundance data, 40 assemblages presented negative values, and only four presented positive values (Fig. 3). We found significant phylogenetic clustering in 33 assemblages with incidence data and in 39 assemblages with abundance data $(P<0.025$, see Table 1). Similar to the NTI results, we did not find 
Fig. 3 Results for the nearest taxon index (NTI) and net relatedness index (NRI) using the phylogenetic structure of 44 Odonata assemblages from the Betione watershed. Positive values indicate communities with overdispersed phylogenetic structure, whereas negative values indicate phylogenetic clustering. $P$ values relate to the two-tailed Wilcoxon test
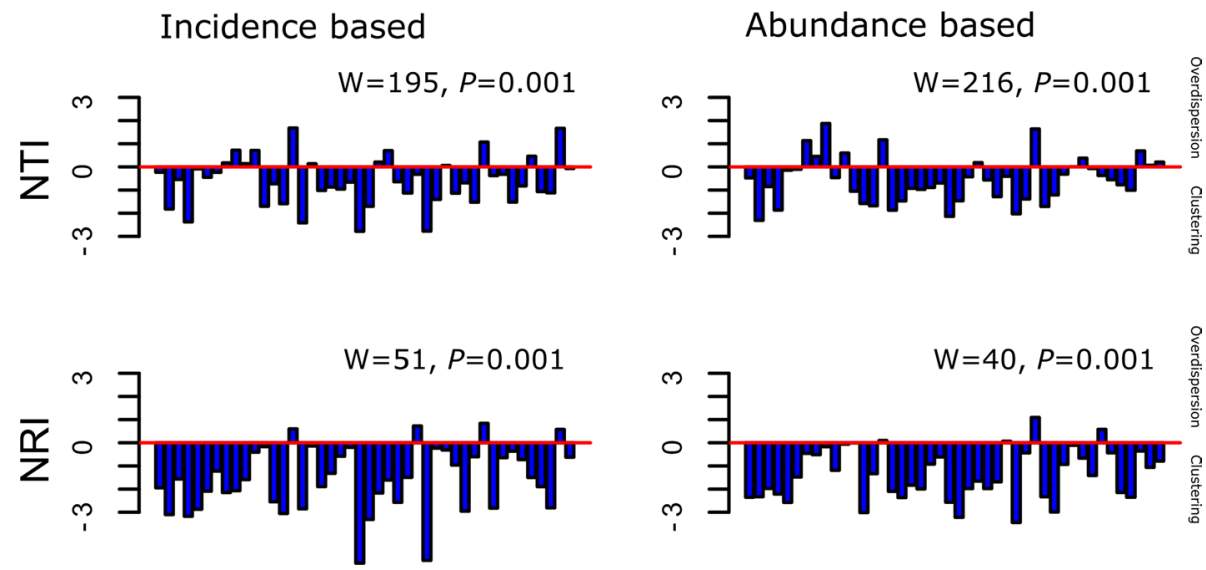

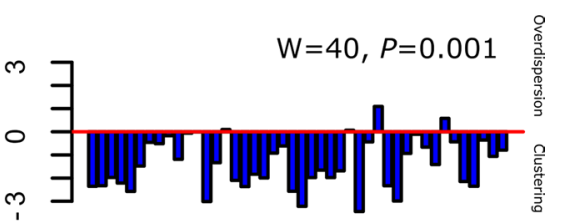

significant phylogenetic overdispersion using NRI. Wilcoxon tests confirmed the overall tendency of NTI and NRI to show phylogenetic clustering when using incidence and abundance data $(P=0.001)$ (Fig. 3). Results showed that odonates are not randomly distributed in local communities, but rather that closely related odonates commonly cooccurred in river stretches.

Observed mean values of phylobetadiversity were lower than expected using incidence and abundance data in both betaMNND and betaMPD $(P<0.02)$. These comparisons between observed phylobetadiversity and null models evidenced a significant effect of phylogenetic relatedness on the beta diversity of Odonata assemblages. Lower than expected values of phylobetadiversity indicate that certain sites generally shared more phylogenetic information than expected. These results suggest that deterministic processes are driving the phylobetadiversity of odonate assemblages, rather than random variation.

Mantel tests showed no correlation between the phylobetadiversity of Odonata assemblages and the riverine gradient in betaMNND or betaMPD using incidence data (Table 2). However, abundance data revealed a marginal correlation using betaMNND $(P=0.067)$ and a significant correlation using betaMPD $(P=0.006$, and see Table 1$)$. These indicate that the abundances of closely related species change depending on the riverine gradient. Similarly, tests of the phylogenetic effect in Mantel correlations when compared with null models only showed a significant effect of phylogeny in betaMPD using abundance data $(P=0.023$, and see Table 1$)$.

The first two RLQ axes (with 66.4 and $21.5 \%$ of the cross-covariance between phylogenetic information and the environment for axes 1 and 2, respectively) summarize the connections between phylogenetic relatedness, species abundance, and environmental variables. The negative (left) part of the first RLQ axis indicates that the abundances of all Anisoptera species and a few Zygoptera species were related to channel width but also to luminosity and aquatic vegetation (Fig. 4). The positive (right) part of the first axis demonstrates that the majority of the zygopterans had abundances that were negatively related to stream width. Anisoptera species tended to inhabit large rivers with higher luminosity, whereas most Zygoptera species were found in shaded and small streams (Fig. 4). The first axis of RLQ therefore summarizes the main environmental gradient of the riverine system. Some Zygoptera species (e.g., Neoneura sylvatica) did not show a negative association of abundance with stream width, but these species also demonstrate phylogenetic conservatism in this preference (e.g., all Neoneura species had abundances that were positively related to stream width, see Fig. 4). The second axis indicates that Argia species abundance was related to site altitude and that the abundances of some species of Anisoptera (e.g., species from genus Micrathyria) were related to luminosity and aquatic vegetation (Fig. 4).

\section{Discussion}

We expected that damselfly and dragonfly assemblages would be phylogenetically overdispersed because their phenotypic similarity is strong enough that closely related species will often attack each other (Anderson and Grether 2010, 2011). Despite expectations, our results indicate that competition among closely related species is not the major driver of the phylogenetic structure of these assemblages. From the perspective of phylogenetic community ecology, our results are not surprising given that phylogenetic clustering is the most common observation and that habitat filtering is a common inference made in other studies (Vamosi et al. 2009; Cavender-Bares et al. 2009). However, the novelty of our study is in assessing a group overlooked by ecophylogenetics (Vamosi et al. 2009) but which is known to show highly aggressive competitive behavior among closely related species. Below, we discuss how similar life strategies should lead to marked habitat filtering, 
Table 1 Values of the nearest taxon index (NTI) and the net relatedness index (NRI) for Odonata assemblages of the Betione watershed, as calculated with incidence and abundance data

\begin{tabular}{|c|c|c|c|c|c|c|c|c|}
\hline \multirow[b]{2}{*}{ Site } & \multicolumn{2}{|c|}{ Incidence-based NTI } & \multicolumn{2}{|c|}{ Abundance-based NTI } & \multicolumn{2}{|c|}{ Incidence-based NRI } & \multicolumn{2}{|c|}{$\begin{array}{l}\text { Abundance-based } \\
\text { NRI }\end{array}$} \\
\hline & Value & $P$ value & Value & $P$ value & Value & $P$ value & Value & $P$ value \\
\hline 1 & -0.232 & 0.400 & -0.477 & 0.337 & -1.945 & 0.041 & -2.352 & 0.029 \\
\hline 2 & -1.818 & 0.035 & -2.309 & 0.008 & -3.102 & 0.010 & -2.327 & 0.035 \\
\hline 3 & -0.544 & 0.310 & -0.847 & 0.219 & -1.563 & 0.070 & -1.972 & 0.048 \\
\hline 4 & -2.373 & 0.011 & -1.863 & 0.028 & -3.175 & 0.014 & -2.214 & 0.044 \\
\hline 5 & -0.084 & 0.474 & -0.142 & 0.448 & -2.869 & 0.017 & -2.575 & 0.026 \\
\hline 6 & -0.448 & 0.333 & -0.103 & 0.434 & -2.091 & 0.057 & -1.479 & 0.100 \\
\hline 7 & -0.234 & 0.404 & 1.133 & 0.875 & -1.225 & 0.096 & -0.457 & 0.267 \\
\hline 8 & 0.174 & 0.568 & 0.454 & 0.666 & -2.149 & 0.037 & -0.515 & 0.276 \\
\hline 9 & 0.720 & 0.753 & 1.874 & 0.963 & -2.069 & 0.034 & -0.169 & 0.376 \\
\hline 10 & 0.141 & 0.558 & -0.462 & 0.354 & -1.590 & 0.067 & -1.188 & 0.127 \\
\hline 11 & 0.710 & 0.751 & 0.598 & 0.720 & -0.405 & 0.271 & -0.060 & 0.382 \\
\hline 12 & -1.700 & 0.044 & -1.051 & 0.168 & -0.166 & 0.373 & -0.010 & 0.393 \\
\hline 13 & -0.729 & 0.238 & -1.578 & 0.063 & -2.546 & 0.027 & -3.012 & 0.013 \\
\hline 14 & -1.588 & 0.063 & -1.676 & 0.043 & -3.054 & 0.009 & -1.335 & 0.104 \\
\hline 15 & 1.680 & 0.970 & 1.171 & 0.873 & 0.599 & 0.724 & 0.096 & 0.413 \\
\hline 16 & -2.414 & 0.018 & -1.868 & 0.057 & -2.853 & 0.015 & -2.100 & 0.044 \\
\hline 17 & 0.138 & 0.556 & -1.468 & 0.074 & -0.138 & 0.407 & -2.366 & 0.028 \\
\hline 18 & -1.016 & 0.166 & -0.925 & 0.154 & -1.891 & 0.079 & -1.834 & 0.077 \\
\hline 19 & -0.870 & 0.201 & -0.971 & 0.186 & -1.321 & 0.085 & -1.993 & 0.053 \\
\hline 20 & -0.959 & 0.180 & -0.888 & 0.200 & -0.582 & 0.227 & -0.921 & 0.145 \\
\hline 21 & -0.659 & 0.265 & -0.697 & 0.266 & -0.196 & 0.333 & -0.613 & 0.212 \\
\hline 22 & -2.782 & 0.004 & -2.137 & 0.002 & -5.197 & 0.001 & -2.567 & 0.017 \\
\hline 23 & -1.702 & 0.051 & -1.462 & 0.066 & -3.312 & 0.008 & -3.218 & 0.011 \\
\hline 24 & 0.208 & 0.568 & -0.426 & 0.335 & -2.170 & 0.037 & -1.979 & 0.050 \\
\hline 25 & 0.703 & 0.754 & 0.186 & 0.566 & -1.609 & 0.075 & -1.656 & 0.068 \\
\hline 26 & -0.639 & 0.262 & -0.561 & 0.310 & -2.572 & 0.028 & -1.977 & 0.053 \\
\hline 27 & -1.128 & 0.136 & -1.285 & 0.105 & -1.494 & 0.078 & -1.685 & 0.062 \\
\hline 28 & -0.320 & 0.375 & -0.406 & 0.316 & 0.726 & 0.764 & 0.067 & 0.478 \\
\hline 29 & -2.773 & 0.006 & -2.027 & 0.022 & -5.076 & 0.001 & -3.441 & 0.006 \\
\hline 30 & -1.405 & 0.090 & -1.387 & 0.100 & -0.233 & 0.316 & -0.438 & 0.254 \\
\hline 31 & 0.060 & 0.517 & 1.640 & 0.938 & -0.311 & 0.284 & 1.094 & 0.913 \\
\hline 32 & -1.134 & 0.140 & -1.709 & 0.037 & -0.963 & 0.148 & -2.328 & 0.035 \\
\hline 33 & -0.693 & 0.256 & -1.211 & 0.130 & -2.953 & 0.018 & -2.988 & 0.020 \\
\hline 34 & -1.525 & 0.064 & -0.313 & 0.382 & -0.604 & 0.241 & -0.935 & 0.166 \\
\hline 35 & 1.074 & 0.860 & 0.007 & 0.484 & 0.841 & 0.830 & -0.110 & 0.384 \\
\hline 36 & -0.375 & 0.364 & 0.380 & 0.629 & -2.822 & 0.021 & -0.663 & 0.201 \\
\hline 37 & -0.320 & 0.380 & -0.069 & 0.481 & -0.641 & 0.215 & -1.414 & 0.087 \\
\hline 38 & -1.522 & 0.069 & -0.370 & 0.343 & -0.362 & 0.297 & 0.577 & 0.700 \\
\hline 39 & -0.820 & 0.214 & -0.553 & 0.307 & -0.729 & 0.199 & -0.435 & 0.255 \\
\hline 40 & 0.459 & 0.656 & -0.772 & 0.241 & -1.499 & 0.069 & -2.147 & 0.054 \\
\hline 41 & -1.064 & 0.149 & -1.007 & 0.171 & -1.892 & 0.041 & -2.350 & 0.032 \\
\hline 42 & -1.122 & 0.130 & 0.692 & 0.776 & -2.811 & 0.018 & -0.355 & 0.306 \\
\hline 43 & 1.665 & 0.961 & 0.070 & 0.555 & 0.577 & 0.721 & -1.063 & 0.189 \\
\hline 44 & -0.067 & 0.468 & 0.209 & 0.592 & -0.622 & 0.221 & -0.792 & 0.162 \\
\hline
\end{tabular}

These two indices correspond to the standardized effect sizes of the metrics mean nearest neighbor distance (MNND) and mean pairwise distance (MDP), respectively. Positive values indicate communities with overdispersed phylogenetic structure and negative values indicate phylogenetic clustering. $P$ values relate to comparisons with null models obtained using communities with random phylogenetic structures 
Table 2 Results of Mantel tests of the correlation between phylogenetic beta diversity and the riverine gradient of the Betione watershed

\begin{tabular}{llll}
\hline & Mantel $R$ & $P$ value & $\begin{array}{l}\text { Phylogenetic } \\
P \text { value }\end{array}$ \\
\hline betaMNND incidence & 0.09 & 0.195 & 0.159 \\
betaMNND abundance & 0.16 & 0.067 & 0.217 \\
betaMPD incidence & 0.09 & 0.201 & 0.321 \\
betaMPD abundance & 0.27 & 0.006 & 0.023 \\
\hline
\end{tabular}

Beta diversity was calculated using the beta mean nearest neighbor distance (betaMNND) and the beta mean pairwise distance (betaMPD), employing incidence and abundance data. The riverine gradient was calculated using data on altitude, stream width, vegetation structure, aquatic vegetation, and luminosity. The phylogenetic effect on the Mantel correlation was calculated by comparing the observed Mantel correlation to 1,000 correlations generated based on random phylogenetic distances among species

structuring the spatial distribution of clades along the riverine longitudinal gradient. However, considering recent criticisms of the phylogenetic community ecology approach (Mayfield and Levine 2010), we also considered the possibility that closely related and competitive species could dominate the preferred habitat in some cases.

The phylogenetic structure found along the riverine gradient sheds light on niche conservatism in the habitat preference of odonates (Wiens et al. 2010). For example, all Anisoptera species were only found in larger stretches, all Argia species were found in abundance in headwater streams, and the two Micrathyria species occurred specifically in waters containing aquatic vegetation. The Betione watershed had a marked gradient in stream width, forest cover, shading, and aquatic vegetation that became evident in the RLQ analysis. This gradient results in species that exhibit distinct life strategies (including ecophysiological requirements and behaviors for thermoregulation), with different sites for reproduction, feeding, and thermoregulation. The ecophysiological hypothesis (De Marco and Resende 2004) predicts changes from narrow and shaded streams hosting small perching species that are dependent on air temperature and able to thermoregulate in shaded areas (Corbet 1999) to large rivers with high levels of sunlight which attract larger species (e.g., Hetaerina and Perithemis species). Moreover, some odonates prefer specific macrophytes on which to perch and lay eggs (Butler and deMaynadier 2007), suggesting that availability of oviposition sites should lead to the clustering of closely related species that share the same oviposition strategy. This would include those that oviposit on macrophytes (i.e., Acanthagrion and Aeshnidae species, Bentes et al. 2014), or drop them into the water (some Orthemis species, Corbet 1999).
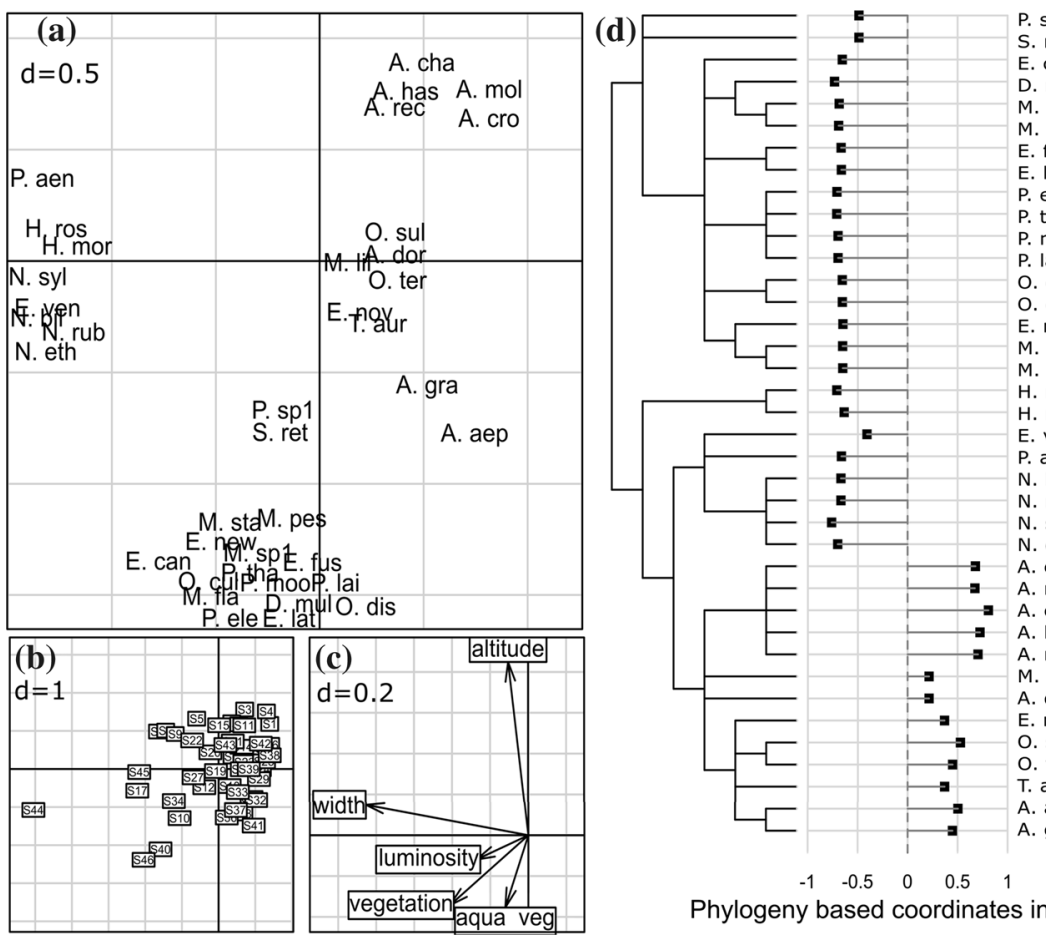

P. sp1 P rogom phus sp 1

S. ret Staurophlebia reticulata

can Elasmoth e m is ca an acrioides

M. fla Macroth e $m$ is fla ye nce ns

E. fus M a croth

E. lat Erythrodiplax lativittata

P. ele $P$ e rithe $m$ is electra

P. tha $P$ e rithe $m$ is tha is

P. mo e rith e $m$ is $m$ oo $m$ a

Perith e $m$ is la is

Orthe $m$ is cultriform is

. dis $O$ the m is d is color

. pes $M$ a nutons antosi

M. pes $M$ icrathyria pese udhypodidy $m$ a

M. sta Micrathyria stawiarskii

H. ros $H$ e ta e rin a rose a

E. ven E pipleone urave ${ }^{2}$ e zuelens is

P. aen Peristicta a eneovirid is

N. bil $N$ e o n e ura biline a ris

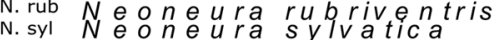

N. syl N e o ne ura syluatica

N. eth N e on e u ra e the la

A. cro A rgia crol A rgia m ollis

A. cha Argia ch a p a d a e

A. has A rgia hasem a $n$

A. rec Argiareclusa

M. lii $M$ etale $p$ to b a sis lillia $n$ a e

A. dor A e olagrion dorsale

E. nov En allagm a hova e his paniae

o. sul O xyagrion $s u I m$ atogrossense

o. ter $\mathrm{O} x$ yagrion te $\mathrm{rm}$ in ale

. aur Tigriagrion a urantinigrum

A. aep Acanthagrion a e piolum
A. gra A canthagrion gracile

Phylogeny based coordinates in axis 1
Fig. 4 Results for the first two axes of RLQ analysis. The first two axes summarize 66.4 and $21.5 \%$ of the cross-covariance between the phylogenetic information and the environmental variables, all weighted by species abundance. a Scores for species on the first two axes. b Scores for sites. $\mathbf{c}$ Coefficients of environmental variables. $\mathbf{d}$ Dot plot of coefficients of phylogenetic information on the first axis next to the phylogenetic tree. The values shown in $\mathbf{d}$ provide the grid size 
Overall, we found that closely related species are likely to have similar life strategies, which generally constrains these species to inhabit similar environments, even if this results in strong aggression between these species.

The association between the phylogenetic structure of odonate assemblages and the riverine gradient was always stronger when using abundance data. The variation in species abundance aids the identification of gradual changes in beta diversity patterns, which may not be possible when exclusively using incidence data (Siqueira et al. 2015). The variation in abundance found in this study was also expected based on the ecophysiological hypothesis (De Marco and Resende 2004); this predicts a decrease in the abundance of Zygoptera from headwaters to large rivers and the opposite pattern for Anisoptera. It is possible that changes in abundance provide more insightful results because the environmental gradient affecting the distribution of odonates does not change abruptly and is not severe enough to eliminate individuals occurring outside their preferred habitat, such as an individual anisopteran that prefers large rivers but can fly over smaller streams.

The explanation above helps us to understand why closely related species prefer similar environments (because of phylogenetically constrained and similar physiological responses), but it does not explain why these similar species share the same environment, often in the presence of strong interference. Coexistence among closely related odonates could occur, for example, because competitive differences among closely related species are low and neutral dynamics control the total abundance of Odonata, independent of species identity (Siepielski et al. 2010). However, our assemblages do not support neutral dynamics because we observed a marked phylogenetic structure along the landscape. We instead suggest that finescale ecological partitioning exists in Odonata assemblages (Siepielski et al. 2011; Siepielski and McPeek 2013). In this view, niche partitioning among closely related species could decrease interspecific interference at levels that facilitate coexistence (Michiels and Dhondt 1987; Dudgeon 1989). For example, congeneric species can have nonoverlapping active periods during the day, decreasing the number of antagonistic encounters among closely related species (Michiels and Dhondt 1987). It is also evident that species sometimes also have different preferred perching heights along the same patch of vegetation, decreasing contested territory (Worthen and Patrick 2004). Specific and fine-scale niche partitioning among closely related species is therefore likely to be an important stabilizing factor that facilitates the co-occurrence of closely related species in odonate assemblages (Siepielski and McPeek 2013).

The phylogenetic community ecology approach has recently faced criticism because some overlooked processes such as asymmetric competition among distantly related species can also drive phylogenetic clustering, as in the case of the habitat filtering effect (Mayfield and Levine 2010). Here, our first assumption was that interference between closely related species should be stronger than that between distantly related species, as previous findings have demonstrated that congenerics attack each other more than distantly related (and morphologically distinct) species (Anderson and Grether 2011). However, mistaken attacks do not discount the possibility that some closely related species may have competitive advantages over other clades, depending on the environment. This may have resulted in more aggressive or stronger competitors dominating preferred environments in some cases, pushing the distribution of weaker competitors or non-territorial species. For instance, experimental studies found that a larger species always won territorial contests against a smaller species when it involved floating vegetation in a river stretch (Tynkkynen et al. 2004), and that the most aggressive species among groups with species of similar size excluded the others from their territories in pond systems (De Marco and Resende 2004). Under this perspective, we hypothesize that in some cases where physiological constraints are not expected to be strong, asymmetric competition may drive phylogenetic clustering and structure of odonate assemblages. Larger stretches with high luminosity would be more prone to co-occurrence of both Anisoptera and Zygoptera species, but competitive asymmetry would affect the abundance of different species and drive the phylogenetic clustering. Zygoptera species may not frequently inhabit larger stretches with high luminosity; this is not necessary because they are not adapted to thermoregulating there, but because they are likely competitively disadvantaged compared to larger species that can only thermoregulate in these sites.

Although competitive asymmetries can occur in some cases, habitat filtering should still be the major driver of community assembly and phylogenetic clustering. This is because some life strategies are strictly related to the environment and should constrain the distribution of some clades irrespectively of competitors. For example: large Anisoptera species are not expected to inhabit shaded streams because of their thermoregulation constraints (De Marco Jr. et al. 2015), while some species cannot lay their eggs in a macrophyte that is not preferred (Butler and deMaynadier 2007), and several Gomphidae species must lay eggs close to sand substrates to enable larval development (McPeek 2008). Consequently, we conclude here that habitat filtering should be the stronger driver of odonate assemblages in most parts of the riverine system. Moreover, some cases of competitive asymmetry should reinforce the relationship between the phylogenetic structure of odonate assemblages and riverine characteristics. 
Acknowledgments The authors thank Dr. Scott Peacor and two anonymous reviewers for comments and suggestions on this manuscript. We are also thankful to Sandrine Pavoine for helping with the RLQ analysis. VSS was supported by grant no. 2013/20540-0, São Paulo Research Foundation (FAPESP). FVN was supported by grant nos. 99999.009654/2014-03 and 1073627, and MER was supported by grant no. 1171579, Coordenação de Aperfeiçoamento de Pessoal de Nível Superior (CAPES). TS was supported by grant no. 2013/50424-1, São Paulo Research Foundation (FAPESP) and by grant no. 480933/2012-0, Conselho Nacional de Desenvolvimento Científico e Tecnológico (CNPq). FOR received a productivity grant, no. 09908/2013-2, from CNPq. The study was partially funded by the Fundect.

Author contributions statement VSS, FVN, and TS formulated the idea for the study. FVN, MER, and FOR organized the sampling design. FVN and MER carried out fieldwork. MER identified the specimens. VSS performed data analysis. VSS and FVN led the writing, and all authors contributed significantly to discussions and improvements to the writing.

\section{References}

Anderson CN, Grether GF (2010) Character displacement in the fighting colours of Hetaerina damselflies. Proc Biol Sci 277:36693675. doi:10.1098/rspb.2010.0935

Anderson CN, Grether GF (2011) Multiple routes to reduced interspecific territorial fighting in Hetaerina damselflies. Behav Ecol 22:527-534. doi:10.1093/beheco/arr013

Bentes SPC, Hamada N, Ferreira-Kleppler RL (2014) Caracterização morfológica de ovos de insetos aquáticos e seus habitats na Amazônia central, Brasil. In: Hamada N, Nessimian JL, Querino RB (eds) Insetos Aquaticos na Amazonia Brasileira: Taxonomia, biologia e ecologia. Editora do INPA, Manaus, pp 51-69

Butler RG, deMaynadier PG (2007) The significance of littoral and shoreline habitat integrity to the conservation of lacustrine damselflies (Odonata). J Insect Conserv 12:23-36. doi:10.1007/ s10841-006-9059-0

Cahill JF, Kembel SW, Lamb EG, Keddy PA (2008) Does phylogenetic relatedness influence the strength of competition among vascular plants? Perspect Plant Ecol Evol Syst 10:41-50. doi:10.1016/j.ppees.2007.10.001

Cavender-Bares J, Ackerly DD, Baum DA, Bazzaz FA (2004) Phylogenetic overdispersion in Floridian oak communities. Am Nat 163:823-843. doi:10.1086/386375

Cavender-Bares J, Kozak KH, Fine PVA, Kembel SW (2009) The merging of community ecology and phylogenetic biology. Ecol Lett 12:693-715. doi:10.1111/j.1461-0248.2009.01314.x

Corbet PS (1999) Dragonflies: behavior and ecology of odonata. Comstock Publ. Assoc., Ithaca

De Marco PJ, Resende DC (2004) Cues for territory choice in two tropical dragonflies. Neotrop Entomol 33:397-401. doi:10.1590/ S1519-566X2004000400001

De Marco P Jr, Batista JD, Cabette HSR (2015) Community assembly of adult odonates in tropical streams: an ecophysiological hypothesis. PLoS One 10:e0123023. doi:10.1371/journal. pone. 0123023

Dijkstra KDB, Kalkman VJ, Dow RA et al (2014) Redefining the damselfly families: a comprehensive molecular phylogeny of Zygoptera (Odonata). Syst Entomol 39:68-96. doi:10.1111/ syen. 12035

Dolédec S, Chessel D, Braak CJF, Champely S (1996) Matching species traits to environmental variables: a new three-table ordination method. Environ Ecol Stat 3:143-166. doi:10.1007/ BF02427859

Dray S, Choler P, Dolédec S et al (2014) Combining the fourth-corner and the RLQ methods for assessing trait responses to environmental variation. Ecology 95:14-21. doi:10.1890/13-0196.1

Dudgeon D (1989) Resource partitioning among Odonata (Insecta: Anisoptera and Zygoptera) larvae in a Hong Kong forest stream. J Zool 217:381-402. doi:10.1111/j.1469-7998.1989.tb02497.x

Dumont HJ, Vierstraete A, Vanfleteren JR (2010) A molecular phylogeny of the Odonata (Insecta). Syst Entomol 35:6-18. doi:10.1111/j.1365-3113.2009.00489.x

Garrison RW, von Ellenrieder N, Louton JA (2006) Dragonfly genera of the New World: an illustrated and annotated key to the Anisoptera. The Johns Hopkins University Press, Baltimore

Garrison RW, von Ellenrieder N, Louton JA (2010) Damselfly genera of the New World: an illustrated and annotated key to the Zygoptera. The Johns Hopkins University Press, Baltimore

Godoy O, Kraft NJB, Levine JM (2014) Phylogenetic relatedness and the determinants of competitive outcomes. Ecol Lett 17:836844. doi:10.1111/ele.12289

Grether GF (2011) The neuroecology of competitor recognition. Integr Comp Biol 51:807-818. doi:10.1093/icb/icr060

Heckman C (2006) Encyclopedia of South American aquatic insects: Odonata-Anisoptera. Illustrated keys to known families, genera, and species in South America. Springer, Washington

Heckman CW (2008) Encyclopedia of South American aquatic insects: Odonata-Zygoptera. Illustrated keys to known families, genera, and species in South America. Springer, Washington

Ives AR, Helmus MR (2010) Phylogenetic metrics of community similarity. Am Nat 176:E128-E142. doi:10.1086/656486

Juen L, De Marco Jr. P (2011) Odonate biodiversity in terra-firme forest streamlets in Central Amazonia: on the relative effects of neutral and niche drivers at small geographical extents. Insect Conserv Divers 4:265-274. doi:10.1111/j.1752-4598.2010.00130.x

Keller D, Holderegger R (2013) Damselflies use different movement strategies for short- and long-distance dispersal. Insect Conserv Divers 6:590-597. doi:10.1111/icad.12016

Kembel SW (2009) Disentangling niche and neutral influences on community assembly: assessing the performance of community phylogenetic structure tests. Ecol Lett 12:949-960. doi:10.1111/j.1461-0248.2009.01354.x

Kraft NJB, Cornwell WK, Webb CO, Ackerly DD (2007) Trait evolution, community assembly, and the phylogenetic structure of ecological communities. Am Nat 170:271-283. doi:10.1086/519400

Lencioni FAA (2005) Damselflies of Brazil: an illustrated identification guide: 1. Non Coenagrionidae families. All Print Editora, São Paulo

Lencioni FAA (2006) Damselflies of Brazil: an illustrated identification guide: 2. Coenagrionidae families. All Print Editora, São Paulo

Mayfield MM, Levine JM (2010) Opposing effects of competitive exclusion on the phylogenetic structure of communities. Ecol Lett 13:1085-1093. doi:10.1111/j.1461-0248.2010.01509.x

McPeek MA (2008) Ecological factors limiting the distributions and abundances of Odonata. In: Córdoba-Aguilar A (ed) Dragonflies and damselflies: model organisms for ecological and evolutionary research. Oxford University Press, Oxford, p 51

Michiels NK, Dhondt AA (1987) Coexistence of three Sympetrum species at Den Diel, Mol, Belgium (Anisoptera: Libellulidae). Odonatologica 16:347-360

Pavoine S, Vela E, Gachet S et al (2011) Linking patterns in phylogeny, traits, abiotic variables and space: a novel approach to linking environmental filtering and plant community assembly. J Ecol 99:165-175. doi:10.1111/j.1365-2745.2010.01743.x

Rehn AC (2003) Phylogenetic analysis of higher-level relationships of Odonata. Syst Entomol 28:181-239. doi:10.1046/j.1365-3113.2003.00210.x 
Rodrigues ME, de Oliveira Roque F, Quintero JMO et al (2016) Nonlinear responses in damselfly community along a gradient of habitat loss in a savanna landscape. Biol Conserv 194:113-120. doi:10.1016/j.biocon.2015.12.001

Sanderson MJ, Purvis A, Henze C (1998) Phylogenetic supertrees: assembling the trees of life. Trends Ecol Evol 13:105-109. doi:10.1016/S0169-5347(97)01242-1

Schultz JK, Switzer PV (2001) Pursuit of heterospecific targets by territorial amberwing dragonflies (Perithemis tenera Say): a case of mistaken identity. J Insect Behav 14:607-620

Siepielski AM, McPeek MA (2013) Niche versus neutrality in structuring the beta diversity of damselfly assemblages. Freshw Biol 58:758-768. doi:10.1111/fwb.12082

Siepielski AM, Hung K-L, Bein EEB, McPeek MA (2010) Experimental evidence for neutral community dynamics governing an insect assemblage. Ecology 91:847-857. doi:10.1890/09-0609.1

Siepielski AM, Mertens AN, Wilkinson BL, McPeek MA (2011) Signature of ecological partitioning in the maintenance of damselfly diversity. J Anim Ecol 80:1163-1173. doi:10.1111/j.1365-2656.2011.01863.x

Singer F (1989) Interspecific aggression in Leucorrhinia dragonflies: a frequency-dependent discrimination threshold hypothesis. Behav Ecol Sociobiol 25:421-427

Siqueira T, Lacerda CG-LT, Saito VS (2015) How does landscape modification induce biological homogenization in tropical stream metacommunities? Biotropica 47:509-516. doi:10.1111/ btp. 12224

Swenson NG (2014) Functional and phylogenetic ecology in R. Springer, New York

Swenson NG, Enquist BJ (2009) Opposing assembly mechanisms in a Neotropical dry forest: implications for phylogenetic and functional community ecology. Ecology 90:2161-2170. doi:10.1890/08-1025.1

Swenson NG, Erickson DL, Mi X et al (2012) Phylogenetic and functional alpha and beta diversity in temperate and tropical tree communities. Ecology 93:S112-S125. doi:10.1890/11-0402.1
Tynkkynen K, Rantala MJ, Suhonen J (2004) Interspecific aggression and character displacement in the damselfly Calopteryx splendens. J Evol Biol 17:759-767. doi:10.1111/j.1420-9101.2004.00733.x

Tynkkynen K, Kotiaho JS, Luojumäki M, Suhonen J (2006) Interspecific territoriality in Calopteryx damselflies: the role of secondary sexual characters. Anim Behav 71:299-306. doi:10.1016/j. anbehav.2005.03.042

Valente-Neto F, de Oliveira Roque F, Rodrigues ME et al (2016) Toward a practical use of Neotropical odonates as bioindicators: testing congruence across taxonomic resolution and life stages. Ecol Indic 61:952-959. doi:10.1016/j.ecolind.2015.10.052

Vamosi JC, Vamosi SM (2007) Body size, rarity, and phylogenetic community structure: insights from diving beetle assemblages of Alberta. Divers Distrib 13:1-10. doi:10.1111/j.1472-4642.2006.00299.x

Vamosi SM, Heard SB, Vamosi JC, Webb CO (2009) Emerging patterns in the comparative analysis of phylogenetic community structure. Mol Ecol 18:572-592. doi:10.1111/j.1365-294X.2008.04001.x

Webb CO (2000) Exploring the phylogenetic structure of ecological communities: an example for rain forest trees. Am Nat 156:145-155

Webb CO, Ackerly DD, McPeek MA, Donoghue MJ (2002) Phylogenies and community ecology. Annu Rev Ecol Evol Syst 33:475-505

Wiens JJ, Ackerly DD, Allen AP et al (2010) Niche conservatism as an emerging principle in ecology and conservation biology. Ecol Lett 13:1310-1324. doi:10.1111/j.1461-0248.2010.01515.x

Worthen WB, Patrick ER (2004) Competitive interactions affect perch-height preferences of three Odonata taxa (Coenagrionidae, Libellulidae). Int J Odonatol 7:529-541. doi:10.1080/13887890. 2004.9748237 